\title{
CUSTOMER IN SERVICE DELIVERY DALAM UPAYA PENINGKATAN JUMLAH NASABAH
}

\author{
Sri Handayani ${ }^{1}$, Jamaluddin $\mathbf{M .}^{2}$ \\ ${ }^{1}$ Mahasiswa Prodi Hukum Ekonomi Syariah FAI Unismuh Makassar \\ ${ }^{2}$ Dosen Prodi Hukum Ekonomi Syariah FAI Unismuh Makassar
}

\begin{abstract}
Abstrak
Penelitian ini bertujuan untuk menganalisis pengaruh dari variabel strategi people (karyawan bank), process (proses pelayanan), serta physical evidence (bukti fisik) terhadap peningkatan jumlah nasabah.

Jumlah sampel yang digunakan dalam penelitian ini sebesar 100 orang responden yang berdomisili di wilayah Makassar. Alat analisis yang dipergunakan adalah regresi linear berganda pada program SPSS.

Hasil Analisis data menunjukkan bahwa semua hipotesis dapat dibuktikan sehingga dapat disimpulkan bahwa peningkatan jumlah nasabah dipengaruhi oleh variabel strategi people(karyawan bank), process(proses), serta physical evidence(bukti fisik). Penelitian ini juga menghubungkan hasil penelitian dengan implikasi teoritis dan implikasi kebijakan bagi manajemen yang diuraikan pada bagian kesimpulan. Keterbatasan penelitian dan agenda penelitian mendatang dapat dijadikan acuan bagi para peneliti berikutnya.
\end{abstract}

Kata Kunci: Customer In Service Delivery, Nasabah

\begin{abstract}
This is study aims to analyze the influence of variable strategy people (employees bank), process (process service), and physical evidence (physical evidence) to increase the number of customers.
\end{abstract}

The number of samples used in this study is 100 respondents who are domiciled in Makassar. Analyzer used is multiple linear regressions in SPSS program.

The result of data analysis shows that all hypotheses can be proved so that it can be concluded that the increase of customer number is influenced by variable of strategy of people (employee of bank), process (process), and physical evidence (physical evidence). This study also links the research results with the theoretical implications and policy implications for management described in the conclusions section. Limitations of research and future research agenda can be used as a reference for the next researchers.

Keywords: Customer in Service Delivery, Customer.

\section{A. PENDAHULUAN}

Pelayanan nasabah bagi dunia perbankan lahir di Amerika Serikat. Konsep ini masuk kedunia perbankan berkat kepopuleran bank asing di
Indonesia karena pelatihan kelompok oleh banknya maupun secara perorangan dan atasannya di tempat kerja. Penyebarannya semakin dipercepat dengan mengetatnya 
persaingan antar bank di Indonesia, yang dipicu oleh kebijakan-kebijakan diregulasi sejak awal 1980-an. Disamping itu semakin banyak mantan manajer bank asing yang menyebar ke berbagai bank umum.

Untuk mempertahankan dan meningkatkan nasabahnya maka bank perlu menjaga citra positif di mata masyarakatnya. Citra ini dapat dibangun melalui kualitas produk, kualitas pelayanan dan kualitas keamanan. Untuk meningkatkan citra perbankan maka bank perlu menyiapkan karyawan yang mampu menangani keinginan dan kebutuhan nasabahnya ini disebut customer in service delivery atau biasa disingkat customer service. Customer service memegang peranan sangat penting dalam dunia perbankan. Tugas utama seorang customer service adalah memberikan pelayanan dan membina hubungan dengan masyarakat.

Customer service bank dalam melayani para nasabah selalu berusaha menarik dengan cara merayu calon nasabah menjadi nasabah bank yang bersangkutan dengan berbagai cara. Customer service juga harus dapat menjaga nasabah lama agar tetap menjadi nasabah bank. Sehubungan dengan peranan itu maka setiap perusahaan memerlukan pelayanan prima yakni suatu sikap atau cara kenyamanan dalam melayani pelanggan secara memuaskan, kepuasan nasabah akan lebih mudah dipenuhi, kalau petugas bank lebih mengenal sifat dan karakter nasabah. Pelayanan yang diberikan oleh customer service haruslah mencerminkan pendekatan seutuhnya dari seorang karyawan bank kepada nasabah. Hal ini dilakukan dengan sikap menolong, bersahabat dan professional yang memuaskan nasabah agar nasabah tersebut datang kembali untuk berbisnis dengan bank kita. Dengan cara seperti itu seorang customer service dapat menikmati pekerjaannya dan memajukan karirnya pada bank tersebut. Permasalahan pokok dalam penelitian ini adalah customer in service delivery berpengaruh terhadap peningkatan jumlah nasabah.

Sesuai Undang-Undang No. 10 Tahun 1998 tentang Perbankan dan Undang-Undang No. 7 Tahun 1992 tentang Perbankan, bank syariah adalah bank umum yang melakukan kegiatan usaha berdasarkan prinsip syariah yang dalam kegiatannya memberikan jasa dalam lalu lintas pembayaran. 
Berbicara mengenai perbankan Islam, pada dasarnya tidak terlepas dari konsep Islam tentang uang. $\mathrm{Di}$ mana uang dalam pandangan Islam merupakan alat tukar dan bukan sebagai komoditi. Diterimanya peranan uang secara luas dimaksudkan agar melenyapkan ketidakadilan, ketidakjujuran dan penghisapan dalam kegiatan ekonomi tukar menukar. Bertolak dari asumsi di atas, pemikiran berdirinya bank Islam bersumber dari adanya larangan riba. Dalam Al-qur'an dan alhadits, pertama dasar perbankan yang bersumber dari salah satu ayat dalam Al-qur'an yang melarang adanya riba adalah surah Al-Baqarah 278 : 279 di mana ayat tersebut membahas masalah riba, karena berbuat riba itu adalah mengambil harta tanpa adanya imbalan yang memadai.

Menurut

Waworuntu (2007:1), istilah "customer in service delivery yang diterjemahkan ke dalam bahasa Indonesia yang artinya pemberian pelayanan kepada nasabah". Di mana untuk bidang bisnis secara umum diartikan sebagai pelayanan pelanggan. Kata customer in service delivery berasal dari empat kata yaitu "customer" sama dengan pelanggan; "in" sama dengan kepada; "service" sama dengan pelayanan; dan "delivery" sama dengan pemberian.

Fungsi customer in service delivery yang harus benar-benar dipahami sehingga perusahaan dapat memberikan pelayanannya secara prima.Prima dalam arti dapat dilaksanakan dengan sebaik-baiknya dan bertanggung jawab dari awal sampai selesainya suatu pelayanan nasabah.

Malayu Hasibuan (2008: 152), mendefinisikan "pelayanan adalah kegiatan pemberian jasa dari suatu pihak kepada pihak lainnya. Pelayanan yang baik adalah pelayanan yang dilakukan secara ramah-tamah, adil cepat, dan dengan etika yang baik sehingga memahami kebutuhan dan kepuasan bagi yang menerimanya".

Pelayanan prima atau layanan unggul itu sendiri adalah bagaimana memberikan layanan maksimal kepada nasabah dan kesigapan dalam mengatasi permasalahan yang muncul secara profesional. Pelayanan ini kemudian akan meninggalkan kesan kepada nasabah sehingga mereka akan seterusnya datang kembali untuk berbisnis dengan bank itu. Pelayanan prima mencerminkan pendekatan 
seutuhnya dari seorang karyawan bank kepada nasabah. Setiap perusahaan memerlukan pelayanan prima, yang dimaksud dengan pelayanan prima adalah, suatu sikap atau cara karyawan dalam melayani pelanggan secara memuaskan.

Menurut Undang-Undang RI nomor 10 tahun 1998 tanggal 10 November1998 tentang perbankan, yang dimaksud dengan "Nasabah adalah pihak yang menggunakan jasa bank atau orang (badan) yang mempunyai rekening simpanan atau pinjaman pada bank." Agar dalam pelayanan yang diberikan benarbenar prima sehingganasabah merasa terpenuhi segala keinginan dan kebutuhannya, maka perusahaanharus mengenal betul karakter nasabah secara umum. Karakter nasabah sulit sekali untuk diidentifikasikan, karena penampilan dan profesi tidak selalu dengan konsisten mencerminkan penampilan seseorang.

\section{B. METODE PENELITIAN}

Penelitian ini yang menjadi populasi adalah jumlah nasabah, berdasarkan populasi tersebut maka ditetapkan sampel sebanyak 100 nasabah dengan menggunakan metode sampling menurut Slovin (Umar : 2000).

Adapun metode pengumpulan data yang digunakan dalam penelitian ini adalah sebagai berikut : Penelitian pustaka (Library research), Penelitian lapang (Field research), Sumber data yang digunakan penulis dalam penelitian ini adalah sebagai berikut : 1) Data primer, yaitu data yang diperoleh dengan mengadakan pengamatan serta wawancara langsung dengan pimpinan dan para karyawan yang ada relevansinya dengan objek penulisan, serta diperoleh dari responden dengan cara pengisian kuesioner yang disediakan. 2) Data sekunder, yaitu data yang diperoleh dengan jalan mengumpulkan dokumen-dokumen serta literatureliteratur yang erat hubungannya dengan penulisan ini.

$$
\text { Variabel yang dianalisis }
$$

dalam penelitian ini dibedakan menjadi variablel dependen dan variabel independen. 1) Variabel dependen (Y) adalah variabel tergantung yang keberadaannya dipengaruhi variabel lainnya. Dalam penelitian ini variabel dependen adalah jumlah nasabah. 2) Variabel independen $(X)$ merupakan variabel bebas yang nantinya akan 
mempengaruhi variabel dependen diperoleh akan dianalisis dengan yang terdiri dari people $\left(\mathrm{X}_{1}\right)$, process SPSS 17 .

$\left(\mathrm{X}_{2}\right)$, physical evidence $\left(\mathrm{X}_{3}\right)$.

Analisis data dilakukan dengan mengukur tingkat korelasi antara variable independen dan dependen, menggunakan analisis regresi berganda. Data yang

C. HASIL PENELITIAN

$\begin{array}{lrr}\text { Deskripsi Variabel Bauran } & \\ \text { Pemasaran Jasa dan } & \\ \text { Perhitungan Skor } & \end{array}$

1. Karyawan Bank (X1)

Tabel. C.1 Tanggapan Responden terhadap variabel people(karyawan bank)

Tingkat Jawaban Responden

\begin{tabular}{|c|c|c|c|c|c|c|c|c|c|c|}
\hline \multirow{2}{*}{ Pertanyaan } & \multicolumn{2}{|c|}{$\begin{array}{l}\text { Sangat } \\
\text { Setuju }\end{array}$} & \multicolumn{2}{|c|}{ Setuju } & \multicolumn{2}{|c|}{ Netral } & \multicolumn{2}{|c|}{$\begin{array}{c}\text { Kurang } \\
\text { Setuju }\end{array}$} & \multicolumn{2}{|c|}{$\begin{array}{c}\text { Tidak } \\
\text { Setuju }\end{array}$} \\
\hline & $\mathbf{F}$ & $\%$ & $\mathbf{F}$ & $\%$ & $\mathbf{F}$ & $\%$ & $\mathbf{F}$ & $\%$ & $\mathbf{F}$ & $\%$ \\
\hline
\end{tabular}

\begin{tabular}{lllllllllllll}
$\begin{array}{c}\text { Komunikasi dengan } \\
\text { pegawai berjalan } \\
\text { dengan lancar }\end{array}$ & 12 & $12 \%$ & 34 & $34 \%$ & 38 & $38 \%$ & 15 & $15 \%$ & 1 & $1 \%$ & 341 \\
\hline $\begin{array}{c}\text { Pegawai memiliki } \\
\text { kompetensi \& } \\
\text { pengetahuan yang baik }\end{array}$ & 16 & $16 \%$ & 23 & $23 \%$ & 38 & $38 \%$ & 19 & $19 \%$ & 4 & $4 \%$ & 328 \\
\hline
\end{tabular}

Pegawai memiliki penampilan yang menarik dan rapi

\begin{tabular}{|c|c|c|c|c|c|c|c|c|c|c|c|}
\hline $\begin{array}{l}\text { Pegawai memberikan } \\
\text { solusi yang } \\
\text { memuaskan terhadap } \\
\text { masalah yang anda } \\
\text { kemukakan }\end{array}$ & 7 & $7 \%$ & 32 & $32 \%$ & 38 & $38 \%$ & 20 & $20 \%$ & 3 & $3 \%$ & 320 \\
\hline $\begin{array}{l}\text { Keluhan anda ditanga } \\
\text { dan direspon dengan }\end{array}$ & & & & & & & & & & & \\
\hline $\begin{array}{c}\text { baik oleh setiap } \\
\text { Pegawai }\end{array}$ & 9 & $9 \%$ & 30 & $30 \%$ & 46 & $46 \%$ & 14 & $14 \%$ & 1 & $1 \%$ & 332 \\
\hline
\end{tabular}


Berdasarkan tabel 5.4

maka dapat diuraikan beberapa tanggapan responden terhadap variabel Karyawan Bank (X1) :

a. Pada indikator pertama yaitu komunikasi pegawai sebanyak 12 orang (12\%) menjawab sangat setuju, 34 orang (34\%) menjawab setuju, 38 orang (38\%) menjawab netral , 15 orang $(15 \%)$ menjawab kurang setuju, dan 1 orang (1\%) menjawab tidak setuju.

b. Pada indikator kedua yaitu kompetensi dan pengetahuan pegawai, sebanyak 16 orang (16\%) menjawab sangat setuju, orang 23 (23\%) menjawab setuju, 38 ( $38 \%)$ menjawab netral, 19 orang (19\%) menjawab kurang setuju, dan 4 orang (4\%) tidak setuju.

c. Pada indikator ketiga yaitu penampilan pegawai, sebanyak 9 orang $(9 \%)$ menjawab sangat setuju, 32 orang (32\%) menjawab setuju, 45 orang (45\%) menjawab netral, 14 orang (14\%) menjawab kurang setuju, dan 0 orang $(0 \%)$ menjawab tidak setuju.

d. Pada Indikator keempat yaitu kemampuan pegawai memberikan solusi, sebanyak 7 orang $(7 \%)$ menjawab sangat setuju, 32 orang (32\%) menjawab setuju, 38 orang (38\%) menjawab netral, 20 orang (20\%) menjawab kurang setuju, dan 3 orang $(3 \%)$ menjawab tidak setuju.

e. Pada Indikator kelima yaitu kemampuan respon pegawai, sebanyak 9 orang $(9 \%)$ menjawab sangat setuju, 30 orang $(30 \%)$ menjawab setuju, 46 orang $(46 \%)$ menjawab netral, 14 orang (14\%) menjawab kurang setuju, dan 1 orang (1\%) menjawab tidak setuju. Dari hasil tersebut dapat disimpulkan bahwa tanggapan konsumen terhadap variabel people sebesar 331,4 berada pada range ketiga yaitu cukup. 


\section{Proses(X2)}

Tabel. C.2: Tanggapan Responden terhadap variabel Process

Tingkat Jawaban Responden

\begin{tabular}{|c|c|c|c|c|c|}
\hline & $\begin{array}{l}\text { Sangat } \\
\text { setuju }\end{array}$ & Setuju & Netral & $\begin{array}{l}\text { Kurang } \\
\text { setuju }\end{array}$ & $\begin{array}{l}\text { Tidak } \\
\text { setuju }\end{array}$ \\
\hline ertanyaan & $\%$ & $\%$ & $\%$ & $\%$ & $\%$ \\
\hline
\end{tabular}

\begin{tabular}{|c|c|c|c|c|c|c|c|c|c|c|c|}
\hline \\
\hline yang cepat & 8 & $8 \%$ & 40 & $39 \%$ & 41 & $41 \%$ & 10 & $10 \%$ & 1 & $1 \%$ & 344 \\
\hline \multicolumn{12}{|l|}{ Ketepatan } \\
\hline pelayanan & 10 & $10 \%$ & 27 & $27 \%$ & 39 & $39 \%$ & 19 & $19 \%$ & 5 & $5 \%$ & 318 \\
\hline \multicolumn{12}{|c|}{ Kenyamanan } \\
\hline \multicolumn{12}{|l|}{ dan } \\
\hline keamanan & 6 & $6 \%$ & 35 & $35 \%$ & 41 & $41 \%$ & 18 & $18 \%$ & 0 & $0 \%$ & 329 \\
\hline nasabah & & & & & & & & & & & \\
\hline
\end{tabular}

Rata-Rata

\section{Sumber : Data diolah, 2014}

Berdasarkan tabel 5.5 maka dapat diuraikan beberapa responden terhadap variable process (X2) :

a. Pada indikator pertama yaitu kecepatan pelayanan, sebanyak 8 orang $(8 \%)$ menjawab sangat setuju, 40 orang (40\%) menjawab setuju, sebanyak 41 orang (41\%) menjawab netral, sebanyak 10 orang (10\%) menjawab kurang setuju, sebanyak 1 orang (1\%) menjawab tidak setuju.

b. Pada indikator kedua yaitu ketepatan dalam pelayanan, sebanyak 10 orang (10\%) menjawab sangat setuju, sebanyak 27 orang (27\%) menjawab setuju, sebanyak 39 orang (39\%) menjawab netral, sebanyak 19 orang (19\%) menjawab kurang setuju, sebanyak 5 orang (5\%) menjawab tidak setuju.

c. Pada indikator ketiga yaitu kenyamanan dan keamanan nasabah, sebanyak 6 orang $(6 \%)$ menjawab sangat setuju, sebanyak 35 orang (35\%) menjawab setuju, sebanyak 41 orang $(41 \%)$ menjawab netral, sebanyak 18 orang (18\%) menjawab kurang setuju. 
Dari hasil tersebut dapat disimpulkan bahwa tanggapan konsumen terhadap variable process yang dimiliki sebesar 330,3 berada pada range ketiga yaitu cukup.
3. Physical Evidence/bukti fisik (X3)

Indikator-indikator dari variabel

Tabel C.3. Tanggapan Responden terhadap variabel Physical Evidence

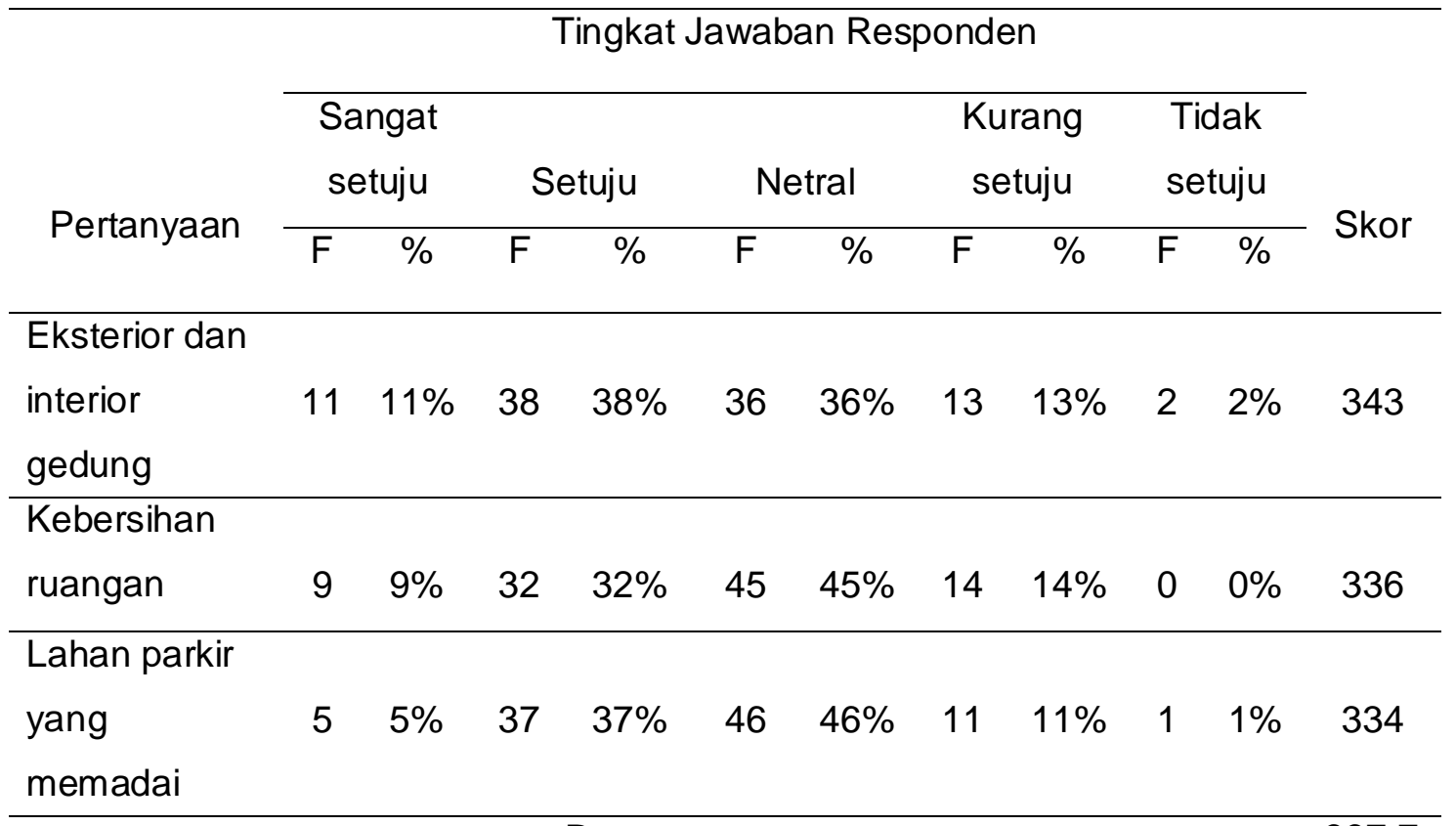

Rata - rata

Sumber : Data diolah, 2014

a. Pada indikator pertama yaitu eksterior dan interior gedung, sebanyak 11 orang (11\%) menjawab sangat setuju, sebanyak 38 orang (38\%) menjawab setuju, sebanyak 36 orang (36\%) menjawab netral, sebanyak 13 orang (13\%) menjawab kurang setuju, sebanyak 2 orang (2\%) menjawab tidak setuju.

b. Pada indikator kedua yaitu kebersihan ruangan, sebanyak
9 orang $(9 \%)$ menjawab sangat setuju, sebanyak 32 orang (32\%) menjawab setuju, sebanyak 45 orang (45\%) menjawab netral, sebanyak 14 orang ( $14 \%$ ) menjawab kurang setuju.

c. Pada indikator ketiga yaitu lahan parkir yang memadai, sebanyak 5 orang (5\%) menjawab sangat setuju, sebanyak 37 orang (37\%) menjawab setuju, sebanyak 46 
orang (46\%) menjawab netral, konsumen terhadap variabel sebanyak 11 orang (11\%) physical evidence yang dimiliki menjawab kurang setuju, sebesar 337,7 berada pada range sebanyak 1 orang (1\%) ketiga yaitu cukup.

menajwab tidak setuju.

Dari hasil tersebut dapat

4. Jumlah Nasabah / Pengambilan keputusan Menabung $(\mathrm{Y})$ disimpulkan bahwa tanggapan

Tabel C.4. Tanggapan Responden terhadap variabel Jumlah Nasabah (Pengambilan Keputusan Menabung)

\begin{tabular}{|c|c|c|c|c|c|c|c|c|c|c|c|}
\hline \multirow{3}{*}{ Pertanyaan } & \multicolumn{10}{|c|}{ Tingkat Jawaban Responden } & \multirow{3}{*}{ Skor } \\
\hline & \multicolumn{2}{|c|}{$\begin{array}{l}\text { Sangat } \\
\text { setuju }\end{array}$} & \multicolumn{2}{|c|}{ Setuju } & \multicolumn{2}{|c|}{ Netral } & \multicolumn{2}{|c|}{$\begin{array}{l}\text { Kurang } \\
\text { setuju }\end{array}$} & \multicolumn{2}{|c|}{$\begin{array}{l}\text { Tidak } \\
\text { setuju }\end{array}$} & \\
\hline & $\mathrm{F}$ & $\%$ & $\mathrm{~F}$ & $\%$ & $\mathrm{~F}$ & $\%$ & $\mathrm{~F}$ & $\%$ & $\mathrm{~F}$ & $\%$ & \\
\hline \multicolumn{12}{|l|}{ Mengenali } \\
\hline kebutuhan & 12 & $12 \%$ & 36 & $36 \%$ & 41 & $41 \%$ & 11 & $11 \%$ & 0 & $0 \%$ & 349 \\
\hline \multicolumn{12}{|l|}{ Pencarian } \\
\hline informasi & 12 & $12 \%$ & 35 & $35 \%$ & 38 & $38 \%$ & 14 & $14 \%$ & 1 & $1 \%$ & 343 \\
\hline \multicolumn{12}{|l|}{ Evaluasi } \\
\hline alternative & 9 & $9 \%$ & 31 & $31 \%$ & 45 & $45 \%$ & 14 & $14 \%$ & 1 & $1 \%$ & 333 \\
\hline \multicolumn{12}{|l|}{ Keputusan } \\
\hline menabung & 9 & $9 \%$ & 32 & $32 \%$ & 41 & $41 \%$ & 18 & $18 \%$ & 0 & $0 \%$ & 332 \\
\hline \multicolumn{12}{|l|}{ Perilaku } \\
\hline pasca & 4 & $4 \%$ & 25 & $25 \%$ & 41 & $41 \%$ & 27 & $27 \%$ & 3 & $3 \%$ & 300 \\
\hline
\end{tabular}

Sumber : Data diolah, 2014

a. Pada indikator pertama yaitu mengenali kebutuhan yaitu sebanyak 12 orang (12\%) menjawab sangat setuju, sebanyak 36 orang (36\%) menjawab setuju, sebanyak 41 orang $(41 \%)$ menjawab netral, sebanyak 11 orang (11\%) menjawab kurang setuju. b. Pada indikator kedua yaitu pencarian informasi yaitu sebanyak 12 orang (12\%) menjawab sangat setuju, sebanyak 35 orang (35\%) menjawab setuju, sebanyak 38 orang (38\%) menjawab netral, sebanyak 14 orang (14\%) menjawab kurang setuju, 
sebanyak 1 orang (1\%) menjawab tidak setuju.

c. Pada indikator ketiga yaitu evaluasi alternatif, yaitu sebanyak 9 orang $(9 \%)$ menjawab sangat setuju, sebanyak 31 orang (31\%) menjawab setuju, sebanyak 45 orang $(45 \%)$ menjawab netral, sebanyak 14 orang (14\%) menjawab kurang setuju, sebanyak 1 orang menjawab tidak setuju.

d. Pada indikator keempat yaitu keputusan menabung yaitu sebanyak 9 orang $(9 \%)$ menjawab sangat setuju, sebanyak 32 orang (32\%) menjawab setuju, sebanyak 4 orang $(41 \%)$ menjawab netral, sebanyak 18 orang (18\%) menjawab kurang setuju.

e. Pada indikator kelima yaitu perilaku pasca menabung yaitu sebanyak 4 orang menjawab sangat setuju, sebanyak 25 orang (25\%) menjawab setuju, sebanyak 41

orang (41\%) menjawab netral, sebanyak 27 orang (27\%) menjawab kurang setuju, sebanyak 3 orang (3\%) menjawab tidak setuju. Dari hasil tersebut dapat disimpulkan bahwa tanggapan konsumen terhadap variabel jumlah nasabah yang dimiliki sebesar 331,4 berada pada range ketiga yaitu cukup.

\section{Hasil Uji Hipotesis}

\section{Uji F ( Simultan)}

Uji F-statistik digunakan untuk membuktikan hipotesis yang menyatakan ada pengaruh antara strategi customer in service delivery (Strategi people, strategi process, strategi physical evidence) secara bersama-sama terhadap jumlah nasabah. Hasil pengujian dengan menggunakan program SPSS release 20.0 for windows dapat dilihat pada tabel berikut dengan tingkat signifikansi 5\% ( $\alpha=0.05)$ 
Tabel C.5. Hasil Uji Simultan

\begin{tabular}{|c|c|c|c|c|c|c|}
\hline & \multicolumn{6}{|c|}{ ANOV $^{b}$} \\
\hline & \multirow[t]{2}{*}{ Model } & Sum Of & Df & Mean & $F$ & Sig. \\
\hline & & Squares & & Square & & \\
\hline 1 & Regression & 32.141 & & 10.714 & 152.289 & $.000^{\mathrm{a}}$ \\
\hline & Residual & 6.754 & & & & \\
\hline & Total & 38.894 & & .070 & & \\
\hline
\end{tabular}

a. Predictors : (Constant), Physical, Process, People

b. Dependent Variable : Peningkatan Nasabah

Sumber : data statistik yang diolah

Berdasarkan hasil pengujian di terikat antara strategi people atas diketahui bahwa Fhitung = terhadap jumlah nasabah ,strategi 152,289 dengan probabilitas (Sig) process terhadap jumlah nasabah, 0.000 . Hasil statistik $F$ table $=2,70$ dan strategi physical evidence sehingga dengan membandingkan statistik Fhitung dengan Ftabel, dimana nilai Fhitung $(152,289)>F_{\text {tabel }}$ $(2,70)$ maka hipotesis yang menyatakan terdapat pengaruh strategi customer in service delivery (Strategi people,h strategi process, dan strategi physical evidence) secara simultan terhadap jumlah nasabah diterima dan berarti ada pengaruh signifikan strategi customer in service delivery sebagai variabel bebas secara simultan terhadap jumlah nasabah sebagai variabel terikat.

\section{Hasil Uji-t (parsial)}

Untuk mengetahui signifikansi pengaruh masing-masing variabel bebas terhadap variabel terhadap jumlah nasabah, maka dalam penelitian dilakukan pengujian terhadap koefisien regresi yaitu dengan uji-t. Hasil pengujian koefisien regresi dapat dilihat pada tabel 5.10. Dari pengujian tersebut diperoleh hasil sebagai berikut ;

a. Signifikansi pengaruh strategi people $\left(\mathrm{X}_{1}\right)$ terhadap jumlah nasabah $(\mathrm{Y})$

Dengan membandingkan statistik hitung dengan statistik tabel. Jika statistik $\mathrm{t}$ hitung< $\mathrm{t}$ tabel , maka $\mathrm{H}_{0}$ diterima. Sedangkan jika Jika statistik $t$ hitung $>t$ tabel , maka $\mathrm{H}_{0}$ ditolak. Berdasarkan hasil uji-t menunjukkan bahwa nilai $t$ hitung sebesar 6,052 
dengan probabilitas

sebesar 0,000. Hasil statistik

ttabel pada tingkat signifikansi

$5 \%$ dengan degree offreedom

$(\mathrm{df})=\mathrm{n}-2$ atau 100-2 $=98$

(pengujian dua sisi), maka

diperoleh ttabel $=1,98847$. Dari

hasil perbandingan terlihat bahwa

nilai thitung $>$ ttabel, maka hipotesis yang menyatakan ada pengaruh strategi people terhadap jumlah nasabah diterima karena nilai $\mathrm{t}$ hitung $>\mathrm{t}$ table.

b. Signifikansi pengaruh strategi process $\left(\mathrm{X}_{2}\right)$ terhadap jumlah nasabah $(\mathrm{Y})$

Dengan membandingkan statistik hitung dengan statistik tabel. Jika statistik $t$ hitung $<t$ tabel , maka $\mathrm{H}_{0}$ diterima. Sedangkan jika Jika statistik $t$ hitung $>t$ tabel , maka $\mathrm{H}_{0}$ ditolak. Berdasarkan hasil uji-t menunjukkan bahwa nilai $t$ hitung sebesar 3,294 dengan probabilitas (Sig.) sebesar 0,001. Hasil statistik ttabel pada tingkat signifikansi $5 \%$ dengan degree offreedom $(\mathrm{df})=\mathrm{n}-2$ atau 100-2 $=98$ (pengujian dua sisi), maka diperoleh tabel $=1,98847$. Dari hasil perbandingan terlihat bahwa nilai thitung> ttabel ,maka hipotesis yang menyatakan ada pengaruh strategi process terhadap jumlah nasabah diterima karena $t$ hitung $>t$ tabel.

c. Signifikansi pengaruh strategi physical evidence $\left(\mathrm{X}_{3}\right)$ terhadap jumlah nasabah(Y). Dengan membandingkan statistik hitung dengan statistik tabel. Jika statistik $t$ hitung $<\mathrm{t}$ tabel, maka $\mathrm{H}_{0}$ diterima. Sedangkan jika Jika statistik $t$ hitung $>\mathrm{t}$ tabel, maka Ho ditolak. Berdasarkan hasil uji$\mathrm{t}$ menunjukkan bahwa nilai $\mathrm{t}$ hitung sebesar 2,962 dengan probabilitas (Sig.) sebesar 0,004 . Hasil statistik ttabel pada tingkat signifikansi $5 \%$ dengan degree offreedom $(\mathrm{df})=\mathrm{n}-2$ atau 100-2 =98 (pengujian dua sisi), maka diperoleh ttabel $=1,98847$. Dari hasil perbandingan terlihat bahwa nilai thitung > ttabel ,maka hipotesis yang menyatakan ada pengaruh strategi physical evidence terhadap jumlah nasabah diterima karena $t$ hitung $>t$ tabel.

\section{KESIMPULAN}

Signifikansi pengaruh strategi karyawan Bank $\left(X_{1}\right)$ terhadap jumlah 
nasabah

(Y).

Dengan

membandingkan statistik hitung dengan statistik tabel. Jika statistik $t$ hitung $<\mathrm{t}$ tabel , maka $\mathrm{H}_{0}$ diterima. Sedangkan jika Jika statistik t hitung> t tabel, maka $\mathrm{H}_{0}$ ditolak. Berdasarkan hasil uji-t menunjukkan bahwa nilai $t$ hitung sebesar 6,052 dengan probabilitas (Sig.) sebesar 0,000 . Hasil statistik tabel pada tingkat signifikansi 5\% dengan degree offreedom (df) $=\mathrm{n}-2$ atau 100-2 $=98$ (pengujian dua sisi), maka diperoleh tabel $=1,98847 . \quad$ Dari hasil perbandingan terlihat bahwa nilai thitung > ttabel, maka hipotesis yang menyatakan ada pengaruh strategi karyawan Bank terhadap jumlah nasabah diterima karena nilai t hitung $>$ t table.

Signifikansi

pengaruh

strategi proses $\left(X_{2}\right)$ terhadap jumlah nasabah (Y) Dengan membandingkan statistik hitung dengan statistik tabel. Jika statistik $t$ hitung $<\mathrm{t}$ tabel, maka $\mathrm{H}_{0}$ diterima. Sedangkan jika Jika statistik $t$ hitung> $\mathrm{t}$ tabel, maka $\mathrm{H}_{0}$ ditolak. Berdasarkan hasil uji-t menunjukkan bahwa nilai $t$ hitung sebesar 3,294 dengan probabilitas (Sig.) sebesar
0,001 . Hasil statistik ttabel pada tingkat signifikansi 5\% dengan degree offreedom (df) = n-2 atau 100-2 $=98$ (pengujian dua sisi), maka diperoleh ttabel $=1,98847 . \quad$ Dari hasil perbandingan terlihat bahwa nilai thitung > ttabel ,maka hipotesis yang menyatakan ada pengaruh strategi proses terhadap jumlah nasabah diterima karena $t$ hitung $>\mathrm{t}$ tabel.

Signifikansi pengaruh strategi bukti fisik $\left(X_{3}\right)$ terhadap jumlah nasabah(Y) Dengan membandingkan statistik hitung dengan statistik tabel. Jika statistik $t$ hitung $<\mathrm{t}$ tabel, maka Ho diterima. Sedangkan jika Jika statistik $t$ hitung $>\mathrm{t}$ tabel , maka $\mathrm{H}_{0}$ ditolak. Berdasarkan hasil uji-t menunjukkan bahwa nilai $t$ hitung sebesar 2,962 dengan probabilitas (Sig.) sebesar 0,004

Hasil statistik ttabel pada tingkat signifikansi 5\% dengan degree offreedom (df) $=\mathrm{n}-2$ atau 100-2 $=98$ (pengujian dua sisi), maka diperoleh ttabel $=1,98847 . \quad$ Dari hasil perbandingan terlihat bahwa nilai thitung> ttabel ,maka hipotesis yang menyatakan ada pengaruh strategi bukti fisik terhadap jumlah nasabah diterima karena $t$ hitung $>t$ tabel. 


\section{DAFT AR PUST AKA}

Bank Sulselbar Syariah. 2011. Buku Panduan Pemasaran Edisi Pertama. Diterbitkan oleh Bank Sulselbar Syariah. Jl. Jenderal Sudirman Kav. 1/Jakarta: 10220 - Indonesia

Arifin, Zainal. 2006. Memahami Bank Syariah. Aksara Baru, Jakarta.

Atmaja, Karnan Purwa. 2005. Apa Bagaimana Bank Islam. PT. Gramedia Pustaka utama, Jakarta.

Dendawijaya, Lukman. 2005.Manajemen Perbankan Edisi Pertama. PT. Ghalia Indonesia, Jakarta.

Hasibuan, Malayu S.P. 2005. Dasar-Dasar Perbankan. PT. Bumi Aksara, Jakarta.

Hurriyati, Ratih. 2005. Bauran Pemasaran dan Loyalitas Konsumen. CV.Alfabeta, Bandung. Kasmir, MM. 2005. Pemasaran Bank. PT. Raja Grafindo, Jakarta.

Maslehuddin. 2005. Bank Syariah Problem dan Prospek Perkembangan di Indonesia. PT. Gunung Agung, Jakarta.

Santoso, Gempur, Drs. 2005. Metodologi Penelitian Kuantitatif \& Kualitatif. Prestasi Pustaka, Jakarta.

Suharta, Ira Prabisma. 2005. Konsep Produk dan Implementasi Operasional Bank Syariah. Pustaka Sinar Harapan. Jakarta.

UU Pokok Perbankan No. 10. 2005. Tentang Pokok Perbankan. Bank Indonesia, Jakarta. Waworuntu, Bob. 2005. Dasar-Dasar Keterampilan Melayani Nasabah Bank. Gramedia Pustaka, Jakarta.

Arifin, Zainul, 1999, Memahami Bank Syariah Lingkup, Peluang, Tantangandan Prospek,Jakarta :Al vabet,

Fuady, Munir, 2007, perbankan modern berdasarkan undang-undang No.10, Bandung: Citra Aditya Bakri.

Fitrianingsi, 2010, Konsep dan Mekanisme Akad Mudharabah Fasilitas Pendanaan Jangka Pendek Syariah, Jakarta : Syarif Hidayatullah

Muhammad. 2005. Konstruksi Mudharabah Dalam Bisnis Syari'ah. Yogyakarta: BPFE- Yogyakarta 